\title{
Fertility-Related Changes in Maternal Body Composition Among the Au of Papua New Guinea
}

\author{
DAVID P. TRACER \\ Department of Anthropology, University of Michigan, Ann Arbor, \\ Michigan 48109
}

\author{
KEY WORDS Reproductive effort, Lactation, Nutritional deple- \\ tion, Adiposity, Lean body mass, Melanesia
}

\begin{abstract}
Evolutionary theory predicts that organisms make trade-offs between their somatic and reproductive energy budgets. Thus every round of reproduction should result in a concomitant decline in the parents' total energy reserves. Among humans this prediction was corroborated more than 25 years ago when fertility-related nutritional depletion was reported among mothers in the Highlands of New Guinea (Jelliffe and Maddocks, 1964). More recently, however, a number of studies of fertility and maternal nutritional status in both developed and developing nations have reported fertility-related increases in various indices of adiposity and lean body mass. Such findings have called the so-called "maternal depletion syndrome" into question, and have raised serious doubts as to whether the phenomenon is widely generalizable to all populations. In light of this recent controversy, data are presented here on fertility-related changes in maternal adiposity and lean body mass among the $\mathrm{Au}$, a lowland forager-horticulturalist population in Papua New Guinea. While both a short-term decline in adiposity following childbirth, and a long-term fertility-related decline are seen among more traditional $\mathrm{Au}$, individuals with a regular source of wage-income show only the former. There are no significant changes in lean body mass with increasing fertility in either group. The finding of significant socioeconomic variation in the capacity to withstand the stress of repeated reproduction even within this one extremely rural area of Papua New Guinea may lend insight into why previous studies have been unable to find evidence of maternal depletion. The fertility-related decline in adiposity that is reported for the more traditional Au is consistent with the predictions of evolutionary theory.
\end{abstract}

The principal that every round of reproduction entails a reduction in an organism's total somatic budget is central in evolutionary theory and forms the underlying basis for much work on the evolution of life history strategies (Calow and Sibly, 1983; Partridge and Harvey, 1985; Shorrocks, 1984). Thus parental investment prenatally, in the conception and gestation of offspring, and postnatally, in the rearing of those offspring to maturity, should result in measurable changes in the parent's energy reserves and, ultimately, should decrease the parent's own probability of survival (Begon and Mortimer, 1986; Fisher, 1958; May and Rubenstein, 1985; Reznick, 1985). There is little reason to assume that humans, especially those living in so-called "traditional" societies, are exempt from this expectation. Rather, Homo sapiens are among the most "K-selected" (Pianka, 1970) of organisms, with weaning of offspring in many societies postponed until 2 years or more postpartum (Bongaarts, 1983; Howell, 1979; Huffman et al., 1980; Konner and Worthman, 1980; Wood et al., 1985) and with offspring remaining dependent on the parent for almost two decades. While the prolongation of parental investment may in fact decrease the cost of investment per unit

Received July 13, 1990; accepted March 18, 1991. 
time, parental investment is still greatest absolutely in the most $\mathrm{K}$-selected species (Prentice and Whitehead, 1987).

Of all the types of effort expended by the mother on her offspring, lactation is perhaps the most costly in terms of energy expenditure per unit time. Indeed, lactation has been shown to draw at least $500 \mathrm{kcal} /$ day from the mother for as long as she continues to breast-feed her infant (Jelliffe, 1976; Prentice and Whitehead, 1987). Among wellnourished mothers of the developed world who typically breast-feed their infants for 2 to 3 months, this cost of lactation is easily buffered by the average $4 \mathrm{~kg}$ fat reserve established during pregnancy (Hytten and Leitch, 1971; Widdowson, 1976). Moreover, where very early supplementation of infants is practiced or breast-feeding is curtailed altogether, parity-specific increases in body weight and fat reserves can be found. Among women of the developing world, however, the combined effects of an often negligible weight gain during pregnancy and prolonged lactation are expected to result in a negative energy balance and thus in a depletion of maternal soft tissue reserves. This prediction was first corroborated by Jelliffe and Maddocks (1964) who reported a high prevalence of protein-calorie malnutrition among multiparous women in the New Guinea Highlands. They referred to this phenomenon as the "maternal depletion syndrome."

More recently, however, studies of energy balance among mothers in a number of developing nations have failed to confirm the existence of the "maternal depletion syndrome" (Adair, 1984; Miller and HussAshmore, 1989; Omran and Standley, 1976; 1981; Prentice et al., 1981). Contrary to the expectations of parental investment theory, all of these studies report either increases in maternal weight-for-height and skinfold thicknesses with parity, or no systematic trend at all. As a result of such findings, the "maternal depletion syndrome" was characterized recently by Thapa et al. (1988) in the journal Nature as "obscure" and "illdefined."

Yet the question of whether parity-specific maternal nutritional depletion is a real phenomenon is by no means trivial. It is well established, for example, that the birth weights of neonates are directly influenced by maternal nutritional status (Frisancho et al., 1985; Habicht et al., 1974; U.S. DHEW, 1980), and that the small-for-date neonate has an elevated risk of early mortality (Federici and Terrenato, 1980; Terrenato et al., 1981). Thus parity-specific levels of maternal nutritional depletion are expected to correlate with declining birth weights and with parity-specific increases in infant mortality.

Parity-specific changes in maternal body composition may also influence fecundability, and hence the length of successive interbirth intervals among already parous women (Delgado et al., 1979; Ellison et al., 1989; Lager and Ellison, 1990). A number of studies have reported, for example, that suckling-induced surges of prolactin in the mother tend to reach higher levels and to remain elevated longer in less well-nourished women (Lunn, 1985; Lunn et al., 1980). Although there is now evidence that lactational amenorrhea may be caused by the action of endogenous opioids such as $\beta$-endorphin rather than prolactin per se (McNeilly, 1988; Short, 1984), there is a strong positive association between levels of these two substances. Hence, parity-specific nutritional depletion may play an important role in influencing both the pulsatile release and clearance of prolactin and $\beta$-endorphin from the maternal blood stream. In addition, a decline in fat reserves as a percentage of overall body mass may act independently to delay the resumption of menses (Frisch, 1985; Frisch and McArthur, 1974), though there has been an ongoing controversy over this (Garn and LaVelle, 1983; Katch and Spiak, 1984; Scott and Johnston, 1985). Still, by whatever mechanism, it is clear that fertility-related fluctuations in maternal energy reserves have the potential to affect future reproductive success.

The present study was conducted with the intent of contributing new data to the debate on fertility-related maternal nutritional depletion. In particular, the aims of this study were 4-fold: (1) to examine short-term changes in body composition during the interval following childbirth among the Au, a rural Papua New Guinea population; (2) to examine the long-term effects of repeated childbearing on maternal adiposity and lean body mass among Au mothers; (3) to examine the effects of socioeconomic status on the ability of $\mathrm{Au}$ mothers to buffer the stress of bearing and raising children; and (4) to attempt to separate the effects of age from those of parity per se on the body composition of the mother. 


\section{MATERIALS AND METHODS} The study population

The $\mathrm{Au}$ live in Sandaun (formerly West Sepik) Province in the northwestern corner of Papua New Guinea at approximately $3^{\circ}$ $33^{\prime}$ south of the equator. They are lowland forest-dwellers inhabiting the southern foothills of the Torricelli Mountains at altitudes less than $900 \mathrm{~m}$. The name "Au" is used here to refer to approximately 10,000 individuals living in the East $\mathrm{Au}$ and West $\mathrm{Au}$ census divisions of Sandaun Province, among whom $\mathrm{Au}$ is the principal, but not the only spoken language. For example, speakers of "Gnau," who are well-known from Lewis' $(1975,1980)$ ethnographic accounts, live well within the boundaries of the Au census districts adjacent to Au speakers, and thus are included here as "Au." In addition, speakers of four other languages ("Alu," "Elkei," "Ghal," and "Yil") who reside within the Au census divisions are included in the present study under the collective name "Au."

Language aside, the $\mathrm{Au}$ are remarkably homogeneous in their patterns of subsistence. They are best characterized as forager-horticulturalists, practicing slash-andburn horticulture, but deriving their dietary staples, the starch of the sago palm (Metroxylon spp.) and the leaves of the jointfir (Gnetum gnemmon), from foraging semiwild stands of these resources.

The Au were chosen as the target population for this study for a number of reasons. First, access to reproductive histories of $\mathrm{Au}$ women collected by a missionary doctor between 1959 and 1979 (see Sturt and Sturt, 1974) have allowed me to confirm the parity and exact ages of approximately two-thirds of the women in the sample. Second, the population suffers from chronic undernutrition and thus even minor perturbations in the energy balance of individuals are expected to lead to measurable changes in soft tissue reserves. Finally, and perhaps most importantly, the use of modern contraceptives is virtually absent from the population. Thus the Au are dependent almost entirely on the contraceptive effect of breast-feeding for regulation of fertility and conform roughly to Henry's definition of a "natural fertility" population (Henry, 1953, 1979). As reported in previous studies (Thomason et al., 1986; Wyatt and Wyatt, 1978), the Au practice a form of extremely prolonged ondemand breast-feeding that is characteristic of many Papua New Guinea populations. Indeed, a probit analysis of data presented in Wyatt and Wyatt (1978) by Tracer and Wood (1986) demonstrated that in $1976,50 \%$ of all mothers in the population still had not weaned their offspring by nearly 3 years postpartum. Since lactation has been hypothesized to be a primary depleting factor in the reproductive process, the extremely prolonged duration of breast-feeding seen among the Au makes them an ideal population in which to study the effects of cumulative fertility on maternal nutritional status.

\section{The sample}

During the period from May 1988 to May 1989 , six surveys of $23 \mathrm{Au}$ villages situated within a $20-\mathrm{km}^{2}$ area were carried out. A total sample of 445 mothers from these villages agreed to participate in the study. All of these mothers had at least one child below the age of 5 years at the time of the survey. In addition, while $89 \%$ of the sample $(n=396)$ had no regular source of income, the other $11 \%(n=49)$ resided in households containing at least one wage-earner. Most of these wage-earners were employed either by the Papua New Guinea government or by local missionaries. Wage-earners are characterized by a diet that tends to be less focused on sago starch, and that incorporates instead a greater proportion of store-bought commodities such as rice and tinned meat or fish. The houses of wage-earners are usually conspicuous in the villages since wage-earners typically forgo the traditional thatched roofing in favor of corrugated iron sheeting.

\section{Data collection}

Interviews were conducted with all women to ascertain both the number of livebirths ever produced as well as the number of children currently living or dead. Women's ages were assessed using the records of the Anguganak Mission Health Centre, and in a small number of cases, using baptismal records of the Catholic Mission at Ningil. The ages obtained from these sources were generally consistent with individual's own assessments of their chronological rank relative to other members of the population.

A series of standard anthropometric measurements including stature, weight, triceps, subscapular, and lateral calf skinfolds, and mid-upper arm and maximum calf circumferences were taken on each woman. Stature was measured with a Martin-type 
anthropometer, weight with an analog readout portable scale, skinfolds with a Lange skinfold caliper, and circumferences with a steel tape. The scale was calibrated at regular intervals using $20 \mathrm{~kg}$ bails of rice. Measurements were performed following the protocols set out in Lohman et al. (1988). All skinfold measurements were repeated three times and the actual data presented in this study are the means of the three measurements. Since individual subjects sometimes refused particular measurements, the sample sizes of the different measurements vary somewhat.

The individual and summed skinfold measurements are used in this study as indices of adiposity or stored energy reserves. From the two circumference measurements, upper-arm and calf muscle areas were computed (Frisancho, 1981). These are used as indices of lean body mass or protein reserves. The convention of using anthropometric measures as indices of energy and protein reserves is well established (Frisancho, 1988).

\section{RESULTS \\ General characteristics of the sample: age and parity}

Table 1 displays the mean number of livebirths ever produced among Au women by 5 year age-classes, and the distribution of parities within each five year age-class. The greatest increase in mean fertility occurs between the $25-29$ and the $30-34$ year ageclasses. The total fertility rate (TFR) in the population, here expressed as the mean fertility among women of postreproductive age (45 years or greater), is 6.1 offspring. If we divide up our sample by socioeconomic status as shown in Table 2, it becomes evident that in all but the 30-34 year age-class, women from a wage-earning household show slightly higher fertility than their non-wageearning counterparts. More interestingly, the number of surviving children is, in general, significantly greater among the wageearners than among the non-wage-earners $(P<.01)$.

\section{General characteristics of the sample: anthropometric measurements}

Table 3 displays the means and standard deviations of the various anthropometric measurements taken on women in the sample. With the exception of subscapular skinfold thickness, all of the measurements fall into the bottom 5 th percentile for age when compared with recently published anthropometric standards for either a combined sample of Whites and African-Americans, or African-Americans alone (Frisancho, 1990). The Au tend to deposit their adipose tissue centripetally, as do other Papua New Guinean populations (Norgan, 1987), and thus their subscapular skinfolds are relatively large when compared to their triceps values. However, these are still below the 25th percentile of subscapular skinfold thickness for U.S. Whites, and below the 15 th percentile for African-Americans. It should also be noted that the low weight of $\mathrm{Au}$ women is not simply a product of their short stature. Even if height is considered, $\mathrm{Au}$ women still fall into the bottom 15th percentile of weightfor-height for either African-Americans alone or the combined sample.

In order to assess the effects of socioeconomic status on the indices of body composition, values for the wage-earning and nonwage-earning $\mathrm{Au}$ were converted to $z$-scores and their means plotted relative to the total population. The results are shown in Figure 1 . The figure shows that wage-earning $\mathrm{Au}$ are uniformly about 1 standard deviation above the population mean for weight, the sum of skinfolds, and the sum of muscle areas, while the non-wage-earning $\mathrm{Au}$ fall below the mean for these variables. Thus socioeconomic variation among women in the sample translates into variation in both adiposity and lean body mass.

\section{Short-term trends in body composition}

Parity-specific nutritional depletion is a cumulative process that is thought to result from the depleting effects of successive rounds of reproduction. Therefore, it stands to reason that $\mathrm{Au}$ mothers should exhibit measurable short-term changes in body composition during the period of lactation that follows the birth of each child. In order to test this proposition, analyses of covariance (ANCOVA) were conducted to examine variation in individual and summed skinfolds, and in individual and summed muscle areas as a function of time since the birth of the last child. Only nonpregnant women were included in these analyses. "Time since last birth" was treated in the ANCOVAs as a categorical variable consisting of three strata: (1) 1 to 2 years postpartum, (2) greater than 2 but less than 4 years postpartum, and (3) 4 to 5 years postpartum. In addition, parity of the 
TABLE 1. Cumulative reproductive performance by 5 year age class among Au women

\begin{tabular}{|c|c|c|c|c|c|c|c|c|c|c|c|c|c|c|}
\hline \multirow[b]{2}{*}{ Age-class } & \multirow[b]{2}{*}{$N$} & \multicolumn{2}{|c|}{ Parity } & \multicolumn{11}{|c|}{ Distribution of parity $(\%)$ in each age class } \\
\hline & & $\bar{X}$ & $\mathrm{SD}$ & 1 & 2 & 3 & 4 & 5 & 6 & 7 & 8 & 9 & 10 & 11 \\
\hline $20-24$ & 79 & 1.62 & .69 & 49.4 & 39.2 & 11.4 & - & - & - & - & - & - & - & - \\
\hline $25-29$ & 117 & 2.45 & 1.19 & 22.2 & 34.2 & 29.9 & 8.5 & 5.1 & - & - & - & - & - & - \\
\hline $30-34$ & 119 & 4.28 & 1.48 & 1.7 & 10.9 & 16.0 & 30.3 & 20.2 & 17.6 & 3.4 & - & - & - & - \\
\hline $35-39$ & 78 & 5.45 & 1.46 & - & 2.6 & 6.4 & 14.1 & 30.8 & 21.8 & 16.7 & 6.4 & 1.3 & - & - \\
\hline $40-44$ & 31 & 5.65 & 1.68 & 3.2 & 3.2 & - & 9.7 & 35.5 & 16.1 & 16.1 & 16.1 & - & - & - \\
\hline $45+$ & 21 & 6.09 & 1.86 & - & 4.8 & - & 4.8 & 28.6 & 33.3 & 9.5 & 9.5 & 4.8 & - & 4.8 \\
\hline
\end{tabular}

TABLE 2. Cumulative reproductive performance by 5 year age class and socioeconomic status among Au women

\begin{tabular}{|c|c|c|c|c|c|c|c|c|}
\hline \multirow[b]{2}{*}{$\begin{array}{l}\text { Age- } \\
\text { class }\end{array}$} & \multicolumn{3}{|c|}{ Wage-earners } & \multicolumn{3}{|c|}{ Non-wage-earners } & \multicolumn{2}{|c|}{$t$-statistic } \\
\hline & $N$ & Parity & $\begin{array}{c}\text { Number } \\
\text { alive }\end{array}$ & $N$ & Parity & $\begin{array}{c}\text { Number } \\
\text { alive }\end{array}$ & Parity & $\begin{array}{c}\text { Number } \\
\text { alive }\end{array}$ \\
\hline $20-24$ & 11 & 2.00 & 2.00 & 68 & 1.56 & 1.40 & $-2.02^{*}$ & $-3.13^{* *}$ \\
\hline $25-29$ & 14 & 3.21 & 3.21 & 104 & 2.35 & 2.10 & -1.58 & $-3.36^{* *}$ \\
\hline $30-34$ & 14 & 3.64 & 3.64 & 106 & 4.36 & 3.50 & 1.69 & -0.58 \\
\hline $35-39$ & 8 & 6.38 & 6.00 & 70 & 5.34 & 4.57 & -1.93 & $-3.04^{* *}$ \\
\hline $40+$ & & & & 49 & 5.82 & 5.10 & & \\
\hline
\end{tabular}

$* P<.05$.

${ }^{* *} P<.01$

${ }^{1}$ The final two columns give the t-statistic obtained when testing for differences between the two socioeconomic strata in parity and offspring survivorship.

TABLE 3. Means and standard deviations of weight, stature, and indices of adiposity and lean body mass used in this study

\begin{tabular}{lrrr}
\hline Variable & $N$ & Mean & SD \\
\hline Weight $(\mathrm{kg})$ & 417 & 46.51 & 6.13 \\
Stature $(\mathrm{cm})$ & 417 & 148.46 & 5.08 \\
Triceps skinfold (mm) & 408 & 5.69 & 2.16 \\
Subscapular skinfold $(\mathrm{mm})$ & 389 & 10.04 & 3.39 \\
Lateral calf skinfold $(\mathrm{mm})$ & 369 & 4.28 & 1.69 \\
Sum of skinfolds $(\mathrm{mm})$ & 344 & 19.81 & 5.48 \\
Upper arm muscle area $\left(\mathrm{cm}^{2}\right)$ & 408 & 29.22 & 4.98 \\
Calf muscle area $\left(\mathrm{cm}^{2}\right)$ & 369 & 62.40 & 8.25 \\
Sum of muscle areas $\left(\mathrm{cm}^{2}\right)$ & 364 & 91.90 & 11.90 \\
\hline
\end{tabular}

mother was included in these analyses as a covariate. This was necessary because women of higher parity could potentially show greater depletion at 1 year postpartum than would women of lower parity at 3 years postpartum. By including parity as a covariate in the ANCOVAs, all of the anthropometric measurements are adjusted for parity of the mother prior to being entered into the analysis of variance.

Table 4 shows the $F$-statistics and significance values attained when testing for differences in the anthropometric variables by time since last birth. It is evident from Table 4 that the indices of adiposity differ significantly among the three strata of time since last parturition. The differences among the indices of lean body mass, however, are uniformly nonsignificant. Of greater interest perhaps, is the pattern of variation in the indices of adiposity among the three strata. Figure 2 illustrates that, as predicted, adiposity declines during the period following any given birth. The sum of skinfolds is highest among women who are between 1 and 2 years since last parturition, and lowest among women who are between 4 and 5 years since last parturition.

\section{Long-term trends in body composition}

In order to test for long-term fertilityrelated trends in the body composition of $\mathrm{Au}$ mothers, a series of ordinary least squares (OLS) regression analyses were performed using log transformations of the sum of skinfolds and the sum of muscle areas as the dependent variables. The logarithmic transformations were performed in order to correct for right skewness in the variables (Sokal and Rohlf, 1981). Parity of the mother, socioeconomic status (SES), elapsed time since last birth (TLB), number of children adopted into the family (ADOPT.IN), and number of children adopted out of the family (ADOPT.OUT) were all included in 


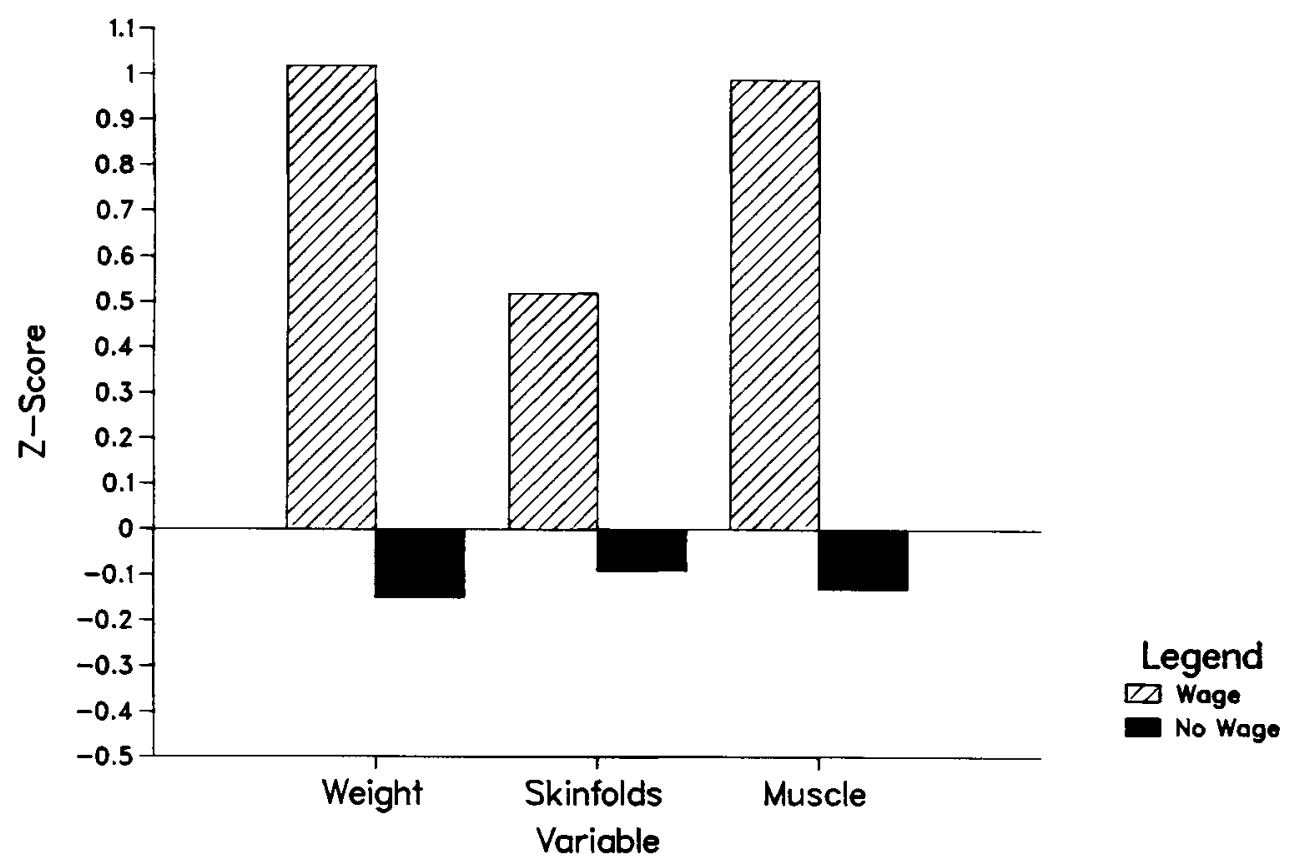

Fig. 1. Weight, the sum of three skinfolds (triceps, subscapula, and calf), and the sum of two muscle areas (upper arm and calf) compared between wage-earners and non-wage-earning $\mathrm{Au}$. All measurements are represented as $z$-scores relative to the total population.

TABLE 4. Results of ANCOVA testing for differences in anthropometric measures among three strata of "time since last birth"]

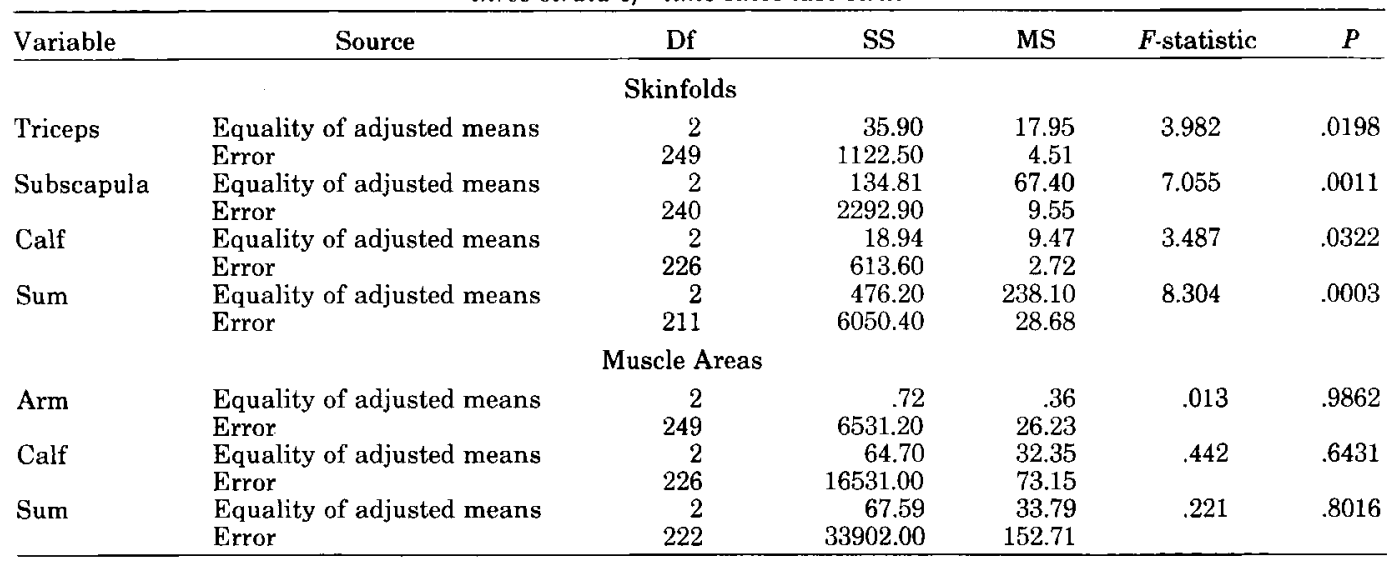

${ }^{1}$ All anthropometric measures are adjusted for parity of the mother.

the analyses as independent variables. Time since the birth of the last child was included in order to control for the confounding effects of the previously demonstrated short-term changes in maternal health on the present analyses of long-term changes. Number of children adopted into or out of families was included in order to gauge whether maternal nutritional status is affected only by the number of reproductive events (pregnancy, parturition, and lactation) experienced by the mother, or whether family size itself has 


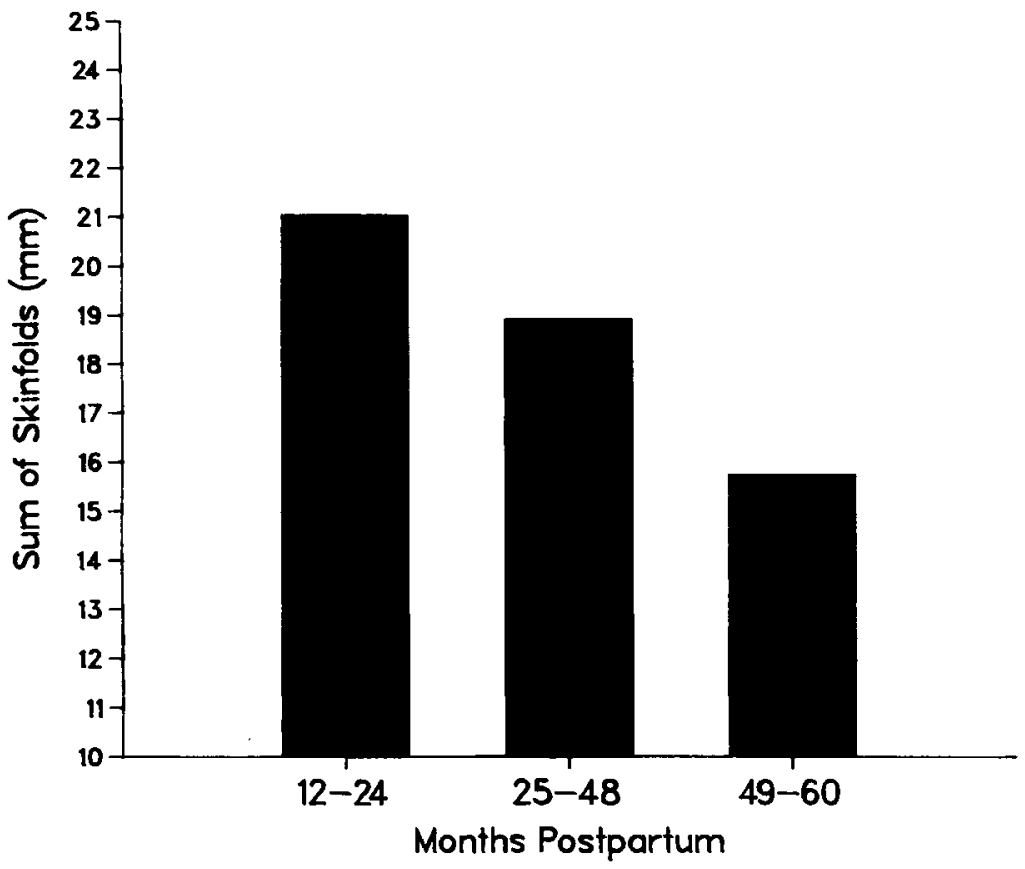

Fig. 2. Sum of skinfolds among Au mothers by number of months since the birth of the last child. All skinfold values have been corrected for parity of the mother.

TABLE 5. Relationship of mother's log sum of skinfolds $(\mathrm{mm})$ and log sum of muscle areas $\left(\mathrm{cm}^{2}\right)$ with parity, socioeconomic status (SES), time since last birth (TLB), and the number of children adopted into (ADOPT.IN) Us. out of (ADOPT.OUT) her family

\begin{tabular}{|c|c|c|c|c|}
\hline $\begin{array}{l}\text { Dependent } \\
\text { variable }\end{array}$ & $\begin{array}{c}\text { Independent } \\
\text { variables }\end{array}$ & Intercept & Coefficient & $P$ \\
\hline \multirow[t]{6}{*}{ Sum of skinfolds ${ }^{1}$} & & 2.4815 & & \\
\hline & PARITY & & -.0575 & .0000 \\
\hline & SES & & .4217 & .0000 \\
\hline & TLB & & -.0019 & .0542 \\
\hline & ADOPT.IN & & .0440 & .5793 \\
\hline & ADOPT.OUT & & -.1015 & .2444 \\
\hline \multirow[t]{5}{*}{ Sum of muscle areas ${ }^{2}$} & & 1.9466 & & \\
\hline & $\begin{array}{l}\text { PARITY } \\
\text { SES }\end{array}$ & & .0004 & $\begin{array}{r}.7867 \\
0000\end{array}$ \\
\hline & TLB & & .0002 & .1468 \\
\hline & ADOPT.IN & & .0282 & .0379 \\
\hline & ADOPT.OUT & & -.0030 & .8491 \\
\hline
\end{tabular}

'Overall model: $F=28.37, P<.0001, r=.50$.

${ }^{2}$ Overall model: $F=5.59, P<.001, r=.24$.

an impact on the indices of maternal health. For example, under conditions of limited resources, larger family size may tax resources more than smaller family size. Alternatively, in societies where children aid in subsistence activities, having a greater number of children can be an economic asset.
Table 5 gives the results of the regressions for the log-transformed indices of maternal adiposity and lean body mass. The table shows that the effects of parity on adiposity are highly significant $(P<.0001)$ with mothers of higher parity having a smaller sum of skinfolds than mothers of lower par- 
ity. There is also a significant, though positive correlation between maternal sum of skinfolds and SES $(P<.0001)$. Time since last birth is negatively correlated with the sum of skinfolds $(P=.05)$, although its effects are not as strong as those of parity. Interestingly, neither the number of children adopted into nor out of families shows any significant relationship with maternal adiposity. Overall, this regression model is highly significant $(P<.0001)$, and shows a relatively high goodness-of-fit.

The regression model for the log-transformed index of maternal lean body mass, the sum of muscle areas, yields results that are somewhat different from those presented above. Parity of the mother shows no significant correlation with the sum of muscle areas $(P=.79)$. The effects of socioeconomic status on maternal lean body mass, however, are both positive and highly significant $(P<.0001)$. Time since last birth, like parity, shows no significant correlation with the sum of muscle areas $(P=.15)$. Finally, the sum of muscle areas shows a positive correlation with the number of children adopted into families $(P=.04)$, but is apparently unrelated to the number of children given up for adoption $(P=.85)$. Overall, this regression model is highly significant $(P<.001)$, but explains relatively little of the variation in lean body mass in the sample.

Although the previous analyses show that maternal adiposity varies inversely with parity of the mother, it is unclear whether this trend holds equally true for both wageearners and non-wage-earners. Therefore, the regression analysis for the sum of skinfolds was repeated separately for each socioeconomic stratum. It should also be noted that since none of the wage-earners reported having given any children up for adoption, this independent variable is omitted in the regressions for the upper SES group. The results of these analyses are presented in Table 6. The table shows that for the nonwage-earners, the inverse relationship between adiposity and parity holds true. The effects of time since last birth, however, are not significant. Among the wage-earning Au, the sum of skinfolds shows no significant relationship with any of the three independent variables.

\section{Controlling for age}

Although there is a clear decline in adiposity with increasing parity among the non- wage-earners, maternal age is highly correlated with parity $(r=.70, P<.0001)$, and thus is a potential confounding factor. For this reason, an attempt was made to factor out the independent effects of age from those of parity on body composition. Although two separate techniques were employed and the results obtained with each are roughly comparable, it should be realized that age and parity are so closely correlated in most populations as to preclude complete control of one or the other in any analysis.

The first technique was also employed by Brush et al. (1983) in their own study of body composition in a New Guinea population. In this method, parity is first regressed as the dependent variable against age of the mother. The residuals of this regression are saved, and are used in subsequent analyses as that part of parity which is largely "ageindependent." When a bivariate OLS regression analysis of the sum of skinfolds and muscle areas is performed using these ageadjusted parity residuals in place of the "raw" parity variable, the results obtained are virtually identical to those presented above. That is, adiposity varies inversely with age-adjusted parity $(P<.005)$ among only the non-wage-earners. There is no significant variation in lean body mass with increasing parity of the mother, however, among either the wage-earners or the nonwage-earning group. It should be noted also, that even in the former analysis of adiposity the correlation coefficient for the regression drops substantially $(r=.20)$. This would seem to indicate that, by eliminating that part of parity which is significantly correlated with age, the model has lost much of its explanatory power, although it still retains its statistical significance.

An alternative method of controlling for age is to forgo statistical analysis in favor of a simple, purely descriptive model of trends in body composition with age and parity. In order to provide such a model, a sample of 305 non-wage-earning Au mothers for whom there was complete data on age, parity, and skinfolds was first divided by decade of life into three age classes. Each age-class was then further stratified by parity, and the mean sum of skinfolds ascertained for each parity- and age-class. The values obtained are given in Table 7, and the trends in sum of skinfolds by age and parity are illustrated in Figure 3.

The plot in Figure 3 suggests that there 
TABLE 6. Relationship of mother's log sum of skinfolds $(\mathrm{mm})$ and log sum of muscle areas (cm ${ }^{2}$ ) with parity, time since last birth (TLB), and the number of children adopted into (ADOPT.IN) vs. out of (ADOPT.OUT) her family for wage-earning and non-wage-earning $A u$

\begin{tabular}{|c|c|c|c|c|}
\hline $\begin{array}{l}\text { Dependent } \\
\text { variable }\end{array}$ & $\begin{array}{c}\text { Independent } \\
\text { variables }\end{array}$ & Intercept & Coefficient & $P$ \\
\hline \multicolumn{5}{|c|}{ Wage-Earners } \\
\hline \multirow{4}{*}{ Sum of skinfolds ${ }^{1}$} & & 2.8587 & & \\
\hline & PARITY & & -.0373 & .1305 \\
\hline & TLB & & -.0041 & .2474 \\
\hline & ADOPT.IN & & -.0145 & .9325 \\
\hline \multicolumn{5}{|c|}{ Non-Wage-Earners } \\
\hline \multirow[t]{5}{*}{ Sum of skinfolds ${ }^{2}$} & & 2.4864 & & \\
\hline & PARITY & & -.0610 & .0000 \\
\hline & TLB & & -.0016 & .1024 \\
\hline & ADOPT.IN & & .0671 & .4663 \\
\hline & ADOPT.OUT & & -.0963 & .2632 \\
\hline
\end{tabular}

'Overall model: $F=1.83, P<.1539, r=.32$.

OVerall model: $F=15.96, P<.0001, r=.38$.

TABLE 7. Means and standard deviations (in parentheses) of sum of skinfolds among non-wage earning Au mothers by parity and decade of life

\begin{tabular}{lcccc}
\hline \multirow{2}{*}{$\begin{array}{c}\text { Age } \\
\text { (years) }\end{array}$} & \multicolumn{4}{c}{ Parity } \\
\cline { 2 - 4 } & 1 & $2-3$ & $4-5$ & $6+$ \\
\hline $20-29$ & $22.1(5.2)$ & $20.1(4.7)$ & $19.9(5.9)$ & - \\
& $n=53$ & $n=80$ & $n=11$ & \\
$30-39$ & $23.8(0.0)$ & $18.3(3.6)$ & $18.1(4.5)$ & $17.6(3.5)$ \\
& $n=1$ & $n=20$ & $n=71$ & $n=45$ \\
$40-49$ & - & - & $16.2(5.4)$ & $15.4(3.0)$ \\
& & & $n=10$ & $n=14$ \\
\hline
\end{tabular}

are independent effects of both age and parity of the mother on the sum of skinfolds. With the exception of a single outlier in the 30-39 age-class at parity 1 (shown in Table 7, but omitted in Figure 3 ), adiposity is highest in the third decade of life and declines rather dramatially through the fourth and fifth decades. Within each age-class though, individuals of higher parity have a smaller sum of skinfolds than their lower parity counterparts. Although it is tempting to suggest that the time since birth of the last child could be longer among higher parity women and that this factor, rather than parity, may account for their smaller skinfolds, this is in fact not the case. While the time elapsed since the last birth is longer by an average of 2 months between women of the 2-3 and 4-5 parity-classes, it is actually shorter by 3.4 months between women of the 4-5 and 6+ parity-classes. Thus Figure 3 suggests that there are independent depleting effects of parity on maternal adiposity among the non-wage-earning Au.

\section{DISCUSSION}

The age and parity characteristics of the $\mathrm{Au}$ are consistent with findings reported for other natural fertility populations. In particular, the total fertility rate of 6.1 children per woman agrees with the finding of Campbell and Wood (1988) that total fertility in most "traditional" noncontracepting human societies tends to vary between four and eight children, with a mean of six. Total fertility is not constant, however, across the two $\mathrm{Au}$ socioeconomic groups. Among all but the 30-34 year age-class, wage-earning Au exhibit both slightly higher fertility and substantially greater offspring survivorship than their non-wage-earning counterparts. This finding is at first glance somewhat paradoxical since in a natural fertility population, greater offspring survival is generally expected to result in longer uninterrupted periods of breast-feeding, longer intervals between births, and, hence, lower fertility (Knodel, 1983; Santow and Bracher, 1984; Suchindran and Adlakha, 1984). In contrast, child death results in truncation of the period of breast-feeding, an earlier return of the mother to a fecundable state, and hence, higher fertility.

The answer to this apparent paradox is that among the $\mathrm{Au}$, the duration of postpartum amenorrhea appears to vary not only with the duration of breast-feeding, but also with the nutritional status of the mother. Therefore, better nourished $\mathrm{Au}$ women resume ovarian cyclicity earlier postpartum than more poorly nourished individuals even though women in the former group tend to 


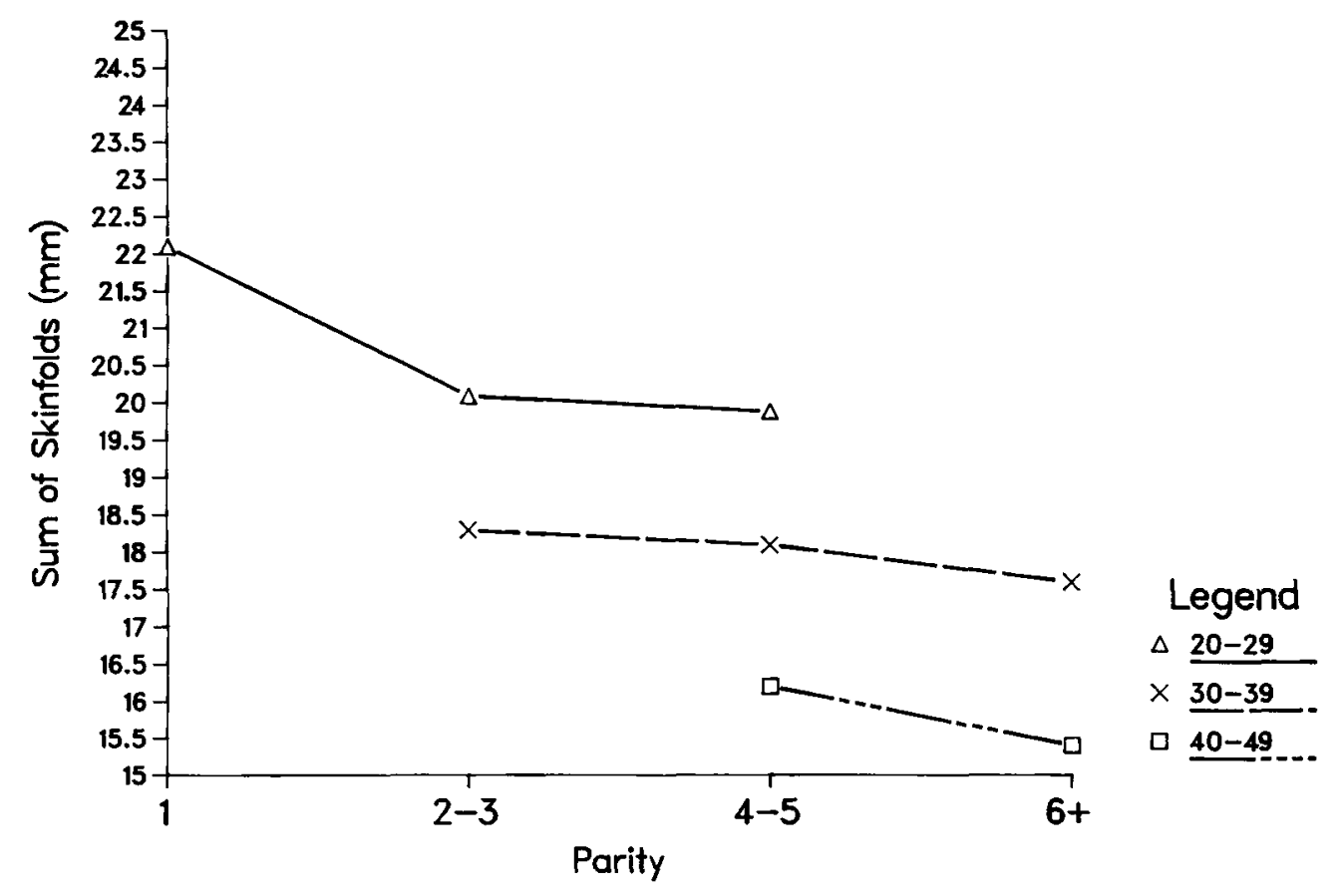

Fig. 3. Mean sum of skinfolds among non-wage-earning Au mothers by parity and decade of life. The data used in this figure are given in Table 6.

breast-feed their offspring for longer on average than those in the latter group (Tracer and Kirshner, 1991).

The general anthropometric characteristics of the Au reveal that even in this remote area of a developing nation, there exists substantial socioeconomic variation in body composition. Moreover, this socioeconomic variation in body composition appears to translate into differential adaptive capacities between the two groups. While the combined sample of wage-earners and nonwage-earners exhibits a short-term decline in energy reserves following the birth of each child, the wage-earners do not exhibit any significant fertility-related variation in either adiposity or lean body mass. Thus individuals in the upper socioeconomic group appear able to withstand the long-term costs of reproduction without significantly compromising either their protein or energy reserves. In contrast, Au mothers who do not have a substantial source of wage income exhibit both short-term losses in fat reserves during the 5-year period immediately following the birth of a child, and a long-term parity-specific decline in adiposity. This fertility related decline amounts to a decrease of approximately $0.70 \mathrm{~mm}$ in the sum of skinfolds per child. Although this amount of fat loss may seem to be rather small, a decrease of $4.2 \mathrm{~mm}$ in the average woman bearing six children is actually rather large, given both the low prepregnancy weight and skinfolds of $\mathrm{Au}$ mothers and the negligible weight gain experienced by them during pregnancy.

The finding that there is substantial socioeconomic variation in the ability of Au mothers to withstand the stress of repeated childbearing is significant. If the small amount of wage income in the higher socioeconomic group is capable of effecting such a large change in their adaptive potential, it is no wonder that some investigators have been unable to find evidence for the maternal depletion syndrome among populations that have a somewhat better nutritional base. In addition, the particular patterns of reproduction followed by women in a given society may also condition their susceptibility to fertility-related nutritional depletion. For 
example, $\mathrm{Au}$ mothers frequently become pregnant while still lactating, and, thus, often do not experience adequate recuperative intervals between births. This stressful reproductive pattern is one that greatly increases the probability that mothers will experience nutritional depletion (Merchant, 1988,1990 ). Therefore, it is essential that future studies of maternal nutritional depletion whether conducted among foragers, forager-horticulturalists, or agriculturalists take account of heterogeneity within the population in access to resources, breastfeeding practices, and long-term patterns of reproduction.

The case for a direct effect of reproductive events per se rather than family size on maternal body composition is strengthened by the finding that parity is a strong predictor of adiposity, while the number of adopted offspring is not. Indeed, there is actually a small though significant tendency for the lean body mass of mothers to increase as the number of children adopted into the family increases. This is probably not a cause and effect relationship, however, but merely indicates a greater propensity on the part of families with adequate resources to adopt children. These families are also the least likely to give children up for adoption; in the current sample there are no cases of a wageearner having given any children up for adoption.

Finally, while adiposity declines with parity among non-wage-earning $\mathrm{Au}$, it is noteworthy that these individuals do not show a similar fertility-related decline in lean body mass. This finding is not entirely unexpected, however, given the particular type of nutritional stress experienced by Au mothers. Unlike the stresses of severe food shortage which tend to be both acute and of short duration, the stresses inherent in successive rounds of pregnancy and lactation are rather more moderate and chronic in nature. Moreover, it is well established that under such conditions of nutritional stress, fat is always catabolized preferentially over muscle mass. In light of these facts, the fertility-related loss of adipose tissue but not of muscle tissue seen among $\mathrm{Au}$ mothers is readily understandable.

In sum, the data presented here strongly suggest that a fertility-related decline in adiposity occurs among Au mothers. These findings corroborate the existence of a longterm "maternal depletion syndrome" as first reported by Jelliffe and Maddocks (1964) in
New Guinea more than 25 years ago. The pattern of parity-specific depletion of fat reserves independent of age seen among the more traditional non-wage-earning Au contrasts sharply with the pattern of long-term fat accretion known to exist among Western populations (Norgan, 1987; Quandt, 1983; Young et al., 1963). It is also consistent with the evolutionary proposition that the expenditure of reproductive effort diminishes both the residual energy reserves and future reproductive value of the parent.

\section{ACKNOWLEDGMENTS}

I gratefully acknowledge the advice and support of A.R. Frisancho, S.M. Garn, and J.W. Wood throughout the course of this research. I also thank G.R. Bentley, C.L. Brace, P.T. Ellison, S. Fields, F.B. Livingstone, V.J. Vitzthum, and C.M. Worthman for their constructive comments on an earlier version of this paper. N.L. Kirshner performed most of the anthropometric measurements used in this study, and played a truly integral role throughout the field portion of this research. For all of her help, I convey my utmost gratitude. I also acknowledge the help of the PNG Institute of Medical Research, the Institute of PNG Studies, the University of PNG Department of Anthropology and Sociology, the staff of the CBC Mission at Anguganak, the Catholic Mission at Ningil, and J. and A. Sturt of Auckland, New Zealand. Funding for this research was provided by the U.S. Dept. of Education Fulbright-Hays Grant G00-87-40-413, Sigma $\mathrm{Xi}$, and the University of Michigan Rackham School of Graduate Studies. Most of all, I thank the $\mathrm{Au}$, not only for participating in this study, but also, for their seemingly endless hospitality. Yi yayim. This manuscript is dedicated to the memory of Suwangi "Rodney" Yasu.

An earlier version of this paper received the Juan Comas Prize at the 59th Annual Meetings of the American Association of Physical Anthropologists, Miami, Florida.

\section{LITERATURE CITED}

Adair LS (1984) Marginal intake and maternal adaptation: the case of rural Taiwan. In $\mathrm{E}$ Pollitt and $\mathrm{P}$ Amante (eds.): Energy Intake and Activity. New York: Alan R. Liss, pp. 33-55.

Begon M, and Mortimer M (1986) Population Ecology: A Unified Study of Animals and Plants. Oxford: Blackwell Scientific Publications.

Bongaarts J (1983) The proximate determinants of natural marital fertility. In RA Bulatao, and RD Lee (eds.): Determinants of Fertility in Developing Coun- 
tries, Vol. 1: Supply and Demand for Children. New York: Academic Press, pp. 103-138.

Brush G, Boyce AJ, and Harrison GA (1983) Associations between anthropometric variables and reproductive performance in a Papua New Guinea highland population. Ann. Hum. Biol. 10:223-234.

Calow P, and Sibley RM (1983) Physiological trade-offs and the evolution of life cycles. Sci. Prog. 68:177-188.

Campbell KL, and Wood JW (1988) Fertility in traditional societies. In PLC Diggory, M Potts, and S Teper (eds.): Natural Human Fertility: Social and Biological Determinants. London: Macmillan, pp. 39-69.

Delgado $H$, Brineman E, Lechtig A, Bongaarts J, Martorell R, and Klein RE (1979) Effect of maternal nutritional status and infant supplementation during lactation on postpartum amenorrhea. Am. J. Obstet. Gynecol. 135:303-307.

Ellison PT, Peacock NR, and Lager C (1989) Ecology and ovarian function among Lese women of the Ituri Forest, Zaire. Am. J. Phys. Anthropol. 78:519-526.

Federici N, and Terrenato L (1980) Biological determinants of early life mortality. In S Preston (ed.): Biological and Social Aspects of Mortality and the Length of Life. Liege: Ordina Editions, pp. 331-361.

Fisher RA (1958) The Genetical Theory of Natural Selection, 2nd rev. ed. New York: Dover.

Frisancho ÁR (1981) New norms of upper limb fat and muscle areas for assessment of nutritional status. Am. J. Clin. Nutr. 34:2540-2545.

Frisancho AR (1988) Nutritional Anthropometry. J. Am. Diet. Assoc. 88:553-555.

Frisancho AR (1990) Anthropometric Standards for the Assessment of Growth and Nutritional Status. Ann Arbor, MI: University of Michigan Press.

Frisancho AR, Matos J, Leonard WR, and Yaroch LA (1985) Developmental and nutritional determinants of pregnancy outcome among teenagers. Am. J. Phys. Anthropol. 66:247-261.

Frisch, RE (1985) Maternal nutrition and lactational amenorrhoea: perceiving the metabolic costs. In $J$ Dobbing (ed.): Maternal Nutrition and Lactational Infertility. New York: Raven Press, pp. 65-91.

Frisch R, and McArthur J (1974) Menstrual cycles: fatness as a determinant of minimum weight for height necessary for their maintenance or onset. Science 185:949-951.

Garn SM, and LaVelle M (1983) Reproductive histories of low weight girls and women. Am. J. Clin. Nutr. $37: 862-866$.

Habicht J-P, Yarbrough C, Lechtig A, and Klein RE (1974) Relation of maternal supplementary feeding during pregnancy to birth weight, and other sociobiological factors. In M Winick (ed.): Nutrition and Fetal Development. New York: John Wiley, pp. 127-145.

Henry L (1953) Fondements théoriques des mesures de la fécondité naturelle. Rev. Inst. Int. Statist. 21:135151.

Henry L (1979) Concepts actuels et resultats empiriques sur la fécondité naturelle. In H Leridon and J Menken (eds.): Natural Fertility. Liege: Ordina Editions, pp. $15-28$.

Howell N (1979) Demography of the Dobe!Kung. New York: Academic Press.

Huffman SL, Chowdhury AKMA, Chakraborty J, and Simpson NK (1980) Breast-feeding patterns in rural Bangladesh. Am. J. Clin. Nutr. 33:144-154.

Hytten FE, and Leitch I (1971) The Physiology of Human Pregnancy, 2nd ed. Oxford: Blackwell Scientific Publications.
Jelliffe DB, and Maddocks I (1964) Notes on ecologic malnutrition in the New Guinea Highlands. Clin. Pediatr. 3:432-438

Jelliffe EFP (1976) Maternal nutrition and lactation. In Breast-feeding and the Mother. Ciba Foundation Symposium 45. Amsterdam: Elsevier, pp. 119-143.

Katch VI, and Spiak DL (1984) Validity of the Mellits and Cheek Method for body fat estimation in relation to menstrual cycle status in athletes and non-athletes below 22 percent fat. Ann. Hum. Biol. 11:389-396.

Knodel J (1983) Natural fertility: age patterns, levels, and trends. In RA Bulatao and RD Lee (eds.): Determinants of Fertility in Developing Countries, Volume 1: Supply and Demand for Children. New York: Academic Press, pp. 61-102

Konner M, and Worthman C (1980) Nursing frequency, gonadal function, and birth spacing among!Kung hunter-gatherers. Science 207:788-791.

Lager C, and Ellison PT (1990) Effect of moderate weight loss on ovarian function assessed by salivary progesterone measurements. Am. J. Hum. Biol. 2:303-312.

Lewis G (1975) Knowledge of Illness in a Sepik Society. London: The Athlone Press.

Lewis G (1980) Day of Shining Red. Cambridge: Cambridge University Press.

Lohman TG, Roche AF, and Martorell R (1988) Anthropometric Standardization Reference Manual. Champaign, IL: Human Kinetics Books.

Lunn PG (1985) Maternal nutrition and lactational infertility: the baby in the driving seat. In J Dobbing (ed.): Maternal Nutrition and Lactational Infertility. New York: Raven Press, pp. 41-64.

Lunn PG, Austin S, Prentice AM, and Whitehead RG (1980) Influence of maternal diet on plasma-prolactin levels during lactation. Lancet 1:623-625.

May RM, and Rubenstein DI (1985) Reproductive strategies. In CR Austin, and RV Short (eds.): Reproduction in Mammals-2nd ed., Book 4: Reproductive Fitness. Cambridge: Cambridge University Press, pp. 1-23.

McNeilly AS (1988) Suckling and the control of gonadotropin secretion. In E Knobil and JD Neill (eds.): The Physiology of Reproduction. New York: Raven Press, pp. 2323-2349.

Merchant K, and Martorell R (1988) Frequent reproductive cycling: Does it lead to nutritional depletion of mothers? Prog. Food Nutr. Sci. 12:339-369.

Merchant K, Martorell R, and Haas J (1990) Consequences for maternal nutrition of reproductive stress across consecutive pregnancies. Am. J. Clin. Nutr. $52: 616-620$.

Miller JE, and Huss-Ashmore R (1989) Do reproductive patterns affect maternal nutritional status?: An analysis of maternal depletion in Lesotho. Am. J. Hum. Biol. 1:409-419.

Norgan NG (1987) Fat patterning in Papua New Guineans: effects of age, sex and acculturation. Am. J. Phys. Anthropol. 74:385-392.

Omran AR, and Standley CC (1976) Family Formation Patterns and Health. Geneva: WHO.

Omran AR, and Standley CC (1981) Further Studies on Family Formation Patterns and Health. Geneva: WHO.

Partridge L, and Harvey PH (1985) Costs of reproduction. Nature (London) 316:20.

Pianka ER (1970) On r- and K-selection. Am. Nat. 104:592-597.

Prentice AM, and Whitehead RG (1987) The energetics of human reproduction. In ASI Loudon and PA Racey 
(eds.): Reproductive Energetics in Mammals. Oxford: Clarendon Press, pp. 275-304.

Prentice AM, Whitehead RG, Robert SB, and Paul AA (1981) Long-term energy balance in child-bearing Gambian women. Am. J. Clin. Nutr. 34:2790-2799.

Quandt SA (1983) Changes in maternal postpartum adiposity and infant feeding patterns. Am. J. Phys. Anthropol. 60:455-461.

Reznick D (1985) Costs of reproduction: An evaluation of the empirical evidence. Oikos 44:257-267.

Santow G, and Bracher MD (1984) Child death and time to next birth in Central Java. Pop. Studies 38:241253.

Scott EC, and Johnston FE (1985) Science, nutrition fat, and policy: Tests of the critical-fat hypothesis. Curr. Anthropol, 26:463-468.

Shorrocks B (ed.) (1984) Evolutionary Ecology. Oxford: Blackwell Scientific Publications.

Short RV (1984) Breast feeding. Sci. Am. 250:35-41.

Sokal RR, and Rohlf JF (1981) Biometry, 2nd ed. New York: W.H. Freeman.

Sturt RJ, and Sturt AE (1974) Natality, fertility, and marriage status in a Sepik River population of New Guinea. Trop. Geogr. Med. 26:399-413.

Suchindran CM, and Adlakha AL (1984) Effect of infant mortality on subsequent fertility of such women in Jordan: A life table analysis. J. Biosoc. Sci, 16:219229.

Terrenato L, Gravina MF, and Ulizzi L (1981) Natural selection associated with birth weight. Ann. Hum. Genet. 45:55-63.

Thapa S, Short RV, and Potts M (1988) Breast feeding, birth spacing and their effects on child survival. Nature (London) 335:679-682.

Thomason JA, Jenkins CL, and Heywood PF (1986) Child feeding patterns amongst the Au of the West Sepik, Papua New Guinea. J. Trop. Pediatr. 32:90-92. Tracer DP, and Kirshner NL (1991) Nutritional determinants of the duration of postpartum amenorrhea in a lowland area of Papua New Guinea. Am. J. Phys. Anthropol., Suppl. 12:174 (abstract).

Tracer DP, and Wood JW (1986) Maternal nutritional depletion, infant mortality, and birth-spacing in Papua New Guinea. Paper presented at the 85 th Annual Meeting of the American Anthropological Association, Philadelphia, PA. Abstracts of the 85th Annual Meeting: 167.

US Department of Health. Education, and Welfare (1980) Factors Associated with Low Birth Weight. DHEW Pub. 80-1915. Hyattesville, MD: Public Health Service.

Widdowson EM (1976) Changes in the body and its organs during lactation: nutritional implications. In Breast-feeding and the Mother. Ciba Foundation Symposium 45. Amsterdam: Elsevier, pp. 103-118.

Wood JW, Johnson PL, and Campbell K (1985) Demographic and endocrinological aspects of low natural fertility in Highland New Guinea. J. Biosoc. Sci. $17: 57-79$

Wyatt JL, and Wyatt GB (1978) A study of the feeding habits and nutrition of children in the Anguganak area of West Sepik. PNG Med. J. 21:184-190.

Young CM, Blondin J, Tensuan R, and Fryer JH (1963) Body composition of "older" women. J. Am. Diet. Assoc. 43:344-348. 